\title{
ENT and dentist cooperation in the management of odontogenic sinusitis. A review
}

\section{La collaborazione tra otorinolaringoiatra e odontoiatra nel trattamento delle sinusiti odontogene}

\author{
Alberto Maria Saibene, Carlotta Pipolo, Roberto Borloni, Giovanni Felisati \\ Head and Neck Department, ASST Santi Paolo e Carlo, Department of Health Sciences, Università degli Studi di Milano, Milan, Italy
}

\begin{abstract}
SUMMARY
Odontogenic sinusitis represents by definition a border condition between otolaryngology and dental science and, from a holistic perspective, cannot be managed without a proficuous collaboration between specialists. This review focus on the different scenarios currently considered by international literature as related to odontogenic sinusitis and sinonasal complications of dental disease or treatment. Consequently, this review will cover all paranasal sinuses infections caused not only by dental disease (e.g. periodontitis and caries), but also by dental procedures (extractions, endodontics and the like), implantological procedures, pre-implantological (maxillary sinus grafting) and medication-related osteonecrosis of the jaw. After dealing with the odontogenic sinusitis diagnostic process and general principles of treatment, we will thoroughly cover odontogenic sinusitis scenarios treatment following an aetiology-based approach. This literature review shows that, albeit more prospective and rigorous studies are badly needed for determining the best treatment for each patient affected by odontogenic sinusitis, the sheer variety of scenarios that may be encountered should be enough to encourage mutual collaboration between ENTs and dentist. Such collaboration is required both to perfect diagnostic and treatment and to provide a solid scientific and medico-legal foundation for each intervention proposed to patients.
\end{abstract}

KEY WORDS: rhinosinusitis, paranasal sinus, endoscopy, computed tomography, Guidelines, dental implants, dental disease, maxillary sinus grafting, maxillary sinus, conebeam computed tomography

\section{RIASSUNTO}

Le sinusiti odontogene rappresentano per definizione una condizione al confine tra otorinolaringoiatria e odontoiatria e, da un punto di vista olistico, non possono essere gestite in assenza di una proficua collaborazione tra specialisti diversi. Questa review si focalizza sui diversi scenari attualmente considerati nella letteratura internazionale come correlati alle sinusiti odontogene e sulle complicanze naso-sinusali di patologia o trattamento odontoiatrico. Conseguentemente, questa review andrà a trattare tutte le infezioni dei seni paranasali causate non solo dalla patologia di interesse odontoiatrico (es. parodontite e carie), ma anche conseguenti a trattamenti odontoiatrici classici (estrazioni, endodonzia, et similia), procedure implantologiche, procedure pre-implantologiche (rialzo del seno mascellare) e osteonecrosi del mascellare da farmaci. Dopo aver trattato la diagnosi delle sinusiti odontogene e i principi generali di terapia, ci focalizzeremo sulla gestione specifica dei singoli quadri di patologia. Questa revisione della letteratura mostra che, per quanto siano fortemente necessari un numero maggiore di studi prospettici per determinare il miglior approccio terapeutico per ciascun paziente affetto da sinusite odontogena, il mero numero di scenari diversi che si possono incontrare dovrebbe essere sufficiente a stimolare la mutua collaborazione tra otorinolaringoiatri e odontoiatri. Tale collaborazione è necessaria per perfezionare la fase diagnostica e di trattamento e per realizzare un solido fondamento scientifico e medico-legale per qualsiasi proposta terapeutica venga rivolta ai pazienti.

PAROLE CHIAVE: rinosinusite, seni paranasali, endoscopia, tomografia computerizzata, linee guida, impianti dentali, rialzo del seno mascellare, seno mascellare, tomografia computerizzata cone beam
Received: October 30, 2020

Accepted: January 23, 2021

Correspondence

Alberto Maria Saibene

Head and Neck Department, ASST Santi Paolo e Carlo, Department of Health Sciences, Università degli Studi di Milano

via di A. di Rudini 8, 20142 Milan, Italy

E-mail: alberto.saibene@gmail.com

Funding

None.

Conflict of interest

The Authors declare no conflict of interest.

How to cite this article: Saibene AM, Pipolo $\mathrm{C}$, Borloni R, et al. ENT and dentist cooperation in the management of odontogenic sinusitis. A review. Acta Otorhinolaryngol Ital 2021;41(SUPPL.1):S116-S123. https://doi. org/10.14639/0392-100X-suppl.1-41-2021-12

(C) Società Italiana di Otorinolaringoiatria e Chirurgia Cervico-Facciale

\section{(c) (i) $\$$}

This is an open access article distributed in accordance with the CC-BY-NC-ND (Creative Commons Attribution-NonCommercial-NoDerivatives 4.0 International) license. The article can be used by giving appropriate credit and mentioning the license, but only for non-commercial purposes and only in the original version. For further information: https:// creativecommons.org/licenses/by-nc-nd/4.0/deed.en 


\section{Introduction}

Since it was first described in the Forties, odontogenic sinusitis (ODS) has represented a common ground for otolaryngologists and dental surgeons ${ }^{1}$.

ODS is far from being the only condition where otolaryngology meets with other specialities, but it is somehow unique in this duality. Where most multidisciplinary teams are usually required for treatment, properly trained specialists should also cooperate for diagnosis ${ }^{2}$.

No single specialist is usually capable of both correctly diagnosing an inflammatory process of the paranasal sinuses, adequately calibrating the tools recommended by international consensus ${ }^{3,4}$, and evaluating the status of teeth and dental prosthetics alike, especially given the high complexity rate the latter achieved in the last decade ${ }^{5}$.

Despite the term ODS referring literally to the inflammatory process of the paranasal sinuses due to diseased teeth, as in the first description of the condition, contemporary scientific literature stretched the term to include other loosely related causes ${ }^{6}$. As a result, ODS covers all paranasal sinuses infections caused not only by dental disease (e.g. periodontitis and caries) but also by dental procedures (extractions, endodontics and the like), implantological procedures, pre-implantological maxillary sinus grafting and medication-related osteonecrosis of the jaw (MRONJ). A composite figure, therefore, emerges, where a complex interplay between otolaryngologists and dental surgeons becomes most often mandatory to understand the bigger picture and correctly manage the patient.

ODS management becomes even more peculiar if we take into account that this protean group of sinonasal conditions lacks shared definition and diagnosis guidelines and the robust literature on the subject is plagued by extreme heterogeneity in defining cases and reporting outcomes. It has to be noted though that, despite guidelines on rhinosinusitis being extremely vague on this subject ${ }^{3}$, ODS is almost universally considered a completely different condition from rhinosinusitis (RS), both in its acute and chronic forms, in terms of pathogenesis, microbiology and response to treatments ${ }^{7,8}$.

A recent multidisciplinary consensus statement ${ }^{9}$ addressed some issues in ODS management after careful revision of scientific literature. The shared statement emerging from the modified Delphi method consensus are resume in Table I and will be further integrated in the following sections of this review.

The most complete existing classification of ODS, defined as the group of sinonasal complications resulting from dental disease or treatment (SCDDT), has been proposed by our group in $2013{ }^{10}$, and has been prospectively vali-
Table I. Multidisciplinary consensus statements on odontogenic sinusitis (from Craig et al., $2020^{9}$, mod.).

Optimal management of ODS involves a shared decision-making process between the otolaryngologist, dental provider, and patient, where the benefits and risks of dental treatment and ESS are discussed

For complicated ODS (orbital or intracranial involvement), patients should undergo ESS, opening all diseased sinuses on CT scan

For ODS patients who have treatable dental pathology, and have minimal or tolerable sinonasal symptoms, primary dental treatment should be pursued

Oral antibiotics alone are not appropriate in the management of ODS due to dental pathology amenable to dental treatments

Once the dental pathology causing ODS has been treated adequately, patients should be followed for at least 1 to 2 months post-treatment to monitor for sinusitis resolution

Balloon sinus dilation may not be appropriate in patients undergoing sinus surgical intervention for ODS given the degree of inflammation and need for definitive sinus drainage

For ODS patients who have treatable dental pathology and have failed primary dental treatment, ESS should be pursued

For ODS patients who have treatable dental pathology, but have significant sinonasal symptoms, primary ESS combined with subsequent dental treatment should be pursued

For ODS due to maxillary dental implants, primary ESS should be pursued in efforts to preserve the dental implant

CT: computed tomography; ESS: endoscopic sinus surgery; ODS: odontogenic sinusitis.

dated ${ }^{11}$ and adopted by other groups, both nationally and internationally ${ }^{12,13}$. The classification (reported in Table II along with the number of patients treated at our institution from 2012 onwards) successfully tries to integrate different etiologies and possible (often multidisciplinary) treatments for possible ODS scenarios. In this review, after dealing with ODS diagnostic process and general principles of treatment, we will thoroughly cover ODS treatment following a similar aetiology-based approach:

- diagnosis of ODS;

- general principles of ODS treatment;

- ODS resulting from dental disease or dental treatments;

- ODS following maxillary sinus grafting;

- ODS following dental implants placement;

- ODS during medication-related osteonecrosis of the jaw (MRONJ).

\section{Review}

Diagnosis of ODS

As a recent systematic review of ODS literature confirmed ${ }^{6}$, studies on the subject are hindered by the general lack of a diagnostic consensus. While RS diagnosis requires symptoms to be confirmed ${ }^{3,4,14}$, many studies diagnose ODS only on the basis of radiological and, less frequently, endoscopic signs only ${ }^{6}$. Furthermore, not all authors agree on which etiologic scenarios to include under the term ODS (and 
Table II. Sinonasal complications of dental disease and treatment classification, with treated cases since 2002.

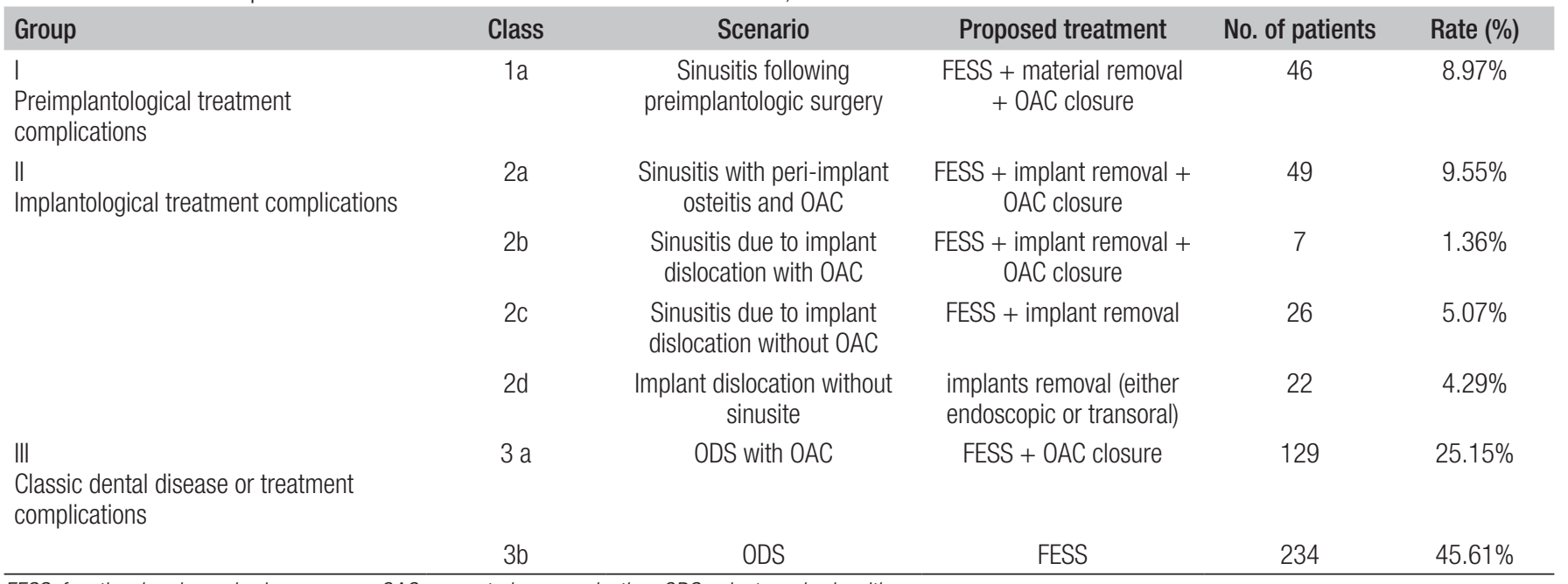

FESS: functional endoscopic sinus surgery; OAC: oro-antral communication; ODS: odontogenic sinusitis.

Table III. Summary of recommendations.

\begin{tabular}{|c|c|}
\hline Clinical scenario & Multidisciplinary management \\
\hline General ODS treatment principles & $\begin{array}{l}\text { Mandatory } \\
\text { - concurrent multidisciplinary management for OS with intraorbital or intracranial } \\
\text { complications or patients with severe symptoms } \\
\text { - two-step multidisciplinary management for conservatively treatable dental problems } \\
\text { in patients with mild symptoms }\end{array}$ \\
\hline Diagnosis of ODS & Strongly recommended \\
\hline ODS resulting from dental disease or dental treatments & $\begin{array}{l}\text { Mandatory } \\
\text { - concurrent multidisciplinary management for existing or expected oro-antral } \\
\text { communications } \\
\text { - two-step multidisciplinary management for conservatively treatable dental problems }\end{array}$ \\
\hline ODS following maxillary sinus grafting & $\begin{array}{c}\text { Mandatory in case of graft infection and displacement for graft removal and OAC } \\
\text { closure }\end{array}$ \\
\hline ODS following dental implants placement & $\begin{array}{c}\text { Strongly recommended for implant removal, mandatory for implant removal in case of } \\
\text { primary ESS failure or for OAC closure }\end{array}$ \\
\hline ODS during MRONJ & Recommended \\
\hline
\end{tabular}

ESS: endoscopic sinus surgery; MRONJ: medication-related osteonecrosis of the jaw; OAC: oro-antral communication; ODS: odontogenic sinusitis.

even on whether or not the term ODS should be used at all). Therefore it seems licit to include until further notice all the aforementioned etiologies. The strong recommendation emerging from the literature ${ }^{7}$ is that both sinusitis AND the odontogenic focus need to be identified for a correct diagnosis of ODS. Consequently, a strict collaboration between the ENT surgeon and an oral surgery specialist is strongly recommended in order to combine the expertise required to avoid ODS overdiagnosis (blatantly inducing consequent overtreatment) and underdiagnosis (which is a known frequent cause of treatment failures in sinus surgery) (Fig. 1) ${ }^{15,16}$. While the clinical examination, both dental and otolaryngological, is straightforward, and the use of nasal endoscopy mandatory, the choice of imaging exams is more complex. Computed tomography (CT) and cone-beam CT (CBCT) are both commonly used for diagnosing sinusitis and identifying the dental problem ${ }^{17,18}$, albeit with different peculiarities (as a general rule, standard CT scan provide a better resolution and contrast for the sinonasal cavities and a better visualization of soft tissues alike, while CBCTs - which represent nevertheless a continuously evolving technology - usually allow for easier diagnosis of dental conditions). However, dental specialists may further require employing techniques such as orthopantomography and periapical radiographs to complete the dental study. Such examination should surely be ordered only by the dental surgeon in selected cases, as not to expose the patient to unnecessary radiation. 


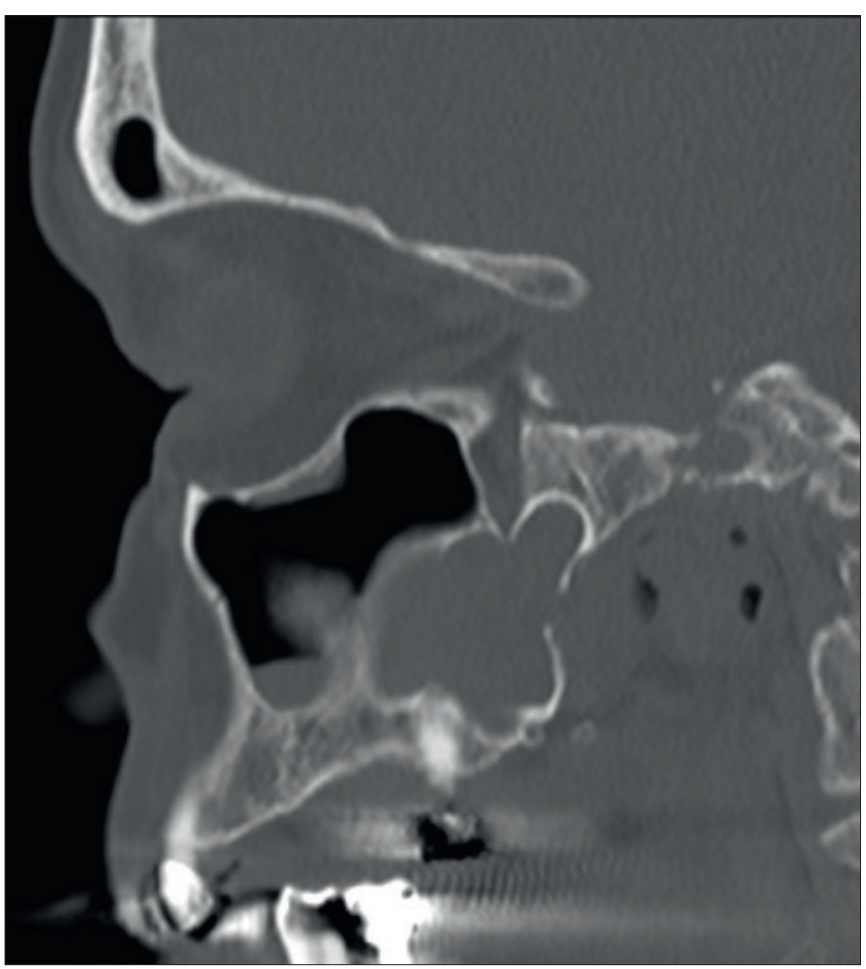

Figure 1. Sagittal CT image showing an odontogenic cyst extending into the body of the sphenoid sinus. Odontogenic sinonasal pathology could represent a matter of difficult differential diagnosis in some patients. A strict collaboration between otolaryngologist and dental specialist is often therefore required also in diagnostic terms.

\section{General principles of ODS treatment}

While it is almost impossible to cover in this review any single clinical picture and the grey areas in between in the galaxy of ODS, there are several general principles that should be taken into account when dealing with this group of conditions, some of which are also reported in Craig and colleagues' statement ${ }^{9}$.

Patient with limited sinusitis symptoms and dental pathology amenable to conservative treatment should seek dental treatment, with endoscopic sinus surgery reserved for nonhealing or relapsing patients. On the other hand, patients with severe symptoms or orbital/intracranial complications should be treated with a combined approach right from the diagnosis, thus allowing for sinus drainage and resolution of the etiological dental focus.

While endoscopic sinus surgery has an undebated role in ODS treatment, the extent of said surgery is still a matter of debate, since some authors ${ }^{19,20}$ proposed that middle antrostomy is enough to warrant patient healing. While prospective validation of these approaches is required, at present opening all sinuses involved in ODS ${ }^{21-23}$, while being the most frequent approach, is recommended only in case of ODS with orbital or intracranial complications ${ }^{9}$. Again, opening the maxillary sinus together with the anterior ethmoid, which represents another frequently adopted surgical choice aimed at restoring a good osteomeatal complex patency, needs further prospective validation before entering routine clinical use.

Last, before delving into the specific etiological pictures, it seems reasonable to raise a warning to the ENT specialist dealing with ODS, a warning that may sound redundant to specialists used to approach this condition. While ODS may appear as a "simpler" version of RS, where the aetiology can be rapidly identified without resourcing to endotypes and interleukin-mediated inflammatory responses, the interplay between teeth and sinuses is extremely complex, and dental causes are often elusive or uncertain. Furthermore, teeth represent an irreplaceable health asset for patients, while dental and/or implantological treatments impose hefty financial and healthcare costs, so any dental procedure, avulsions first and foremost, have to be supported by case-specific clinical evidence. Following these considerations, the statement "a shared decision-making process between the otolaryngologist, dental provider, and patient, where the benefits and risks of dental treatment and endoscopic sinus surgery (ESS) are discussed" opening Craig and colleagues' consensus ${ }^{9}$ should become a mantra in treating ODS, not to turn the ENT-dentist dialogue into a dangerous Mexican standoff with the patient.

\section{ODS resulting from dental disease or dental treatments}

The most classic aetiology of ODS represents, at the same time, the widest and most diverse chapter to explore. Among dental conditions capable of inducing sinusitis it is worth citing periapical infections, caries-related tooth decay, unerupted teeth (Fig. 2) and odontogenic cysts infections; classic dental treatments which may lead to ODS are represented by failed endodontic treatments (either incomplete or overflowing into the sinus) and extractions (resulting in either oro-antral communications - OAC - or displacement of tooth/dental fragments/dental tools fragments into the sinonasal complex) ${ }^{12,24}$.

While cases pertaining to this aetiology may appear extremely varied in presentation and sinus involvement, there are several standpoints than can help the collaboration between otolaryngologist and dental surgeon.

A simple but nevertheless fundamental distinction is between patients with and without OAC (Fig. 3), as originally proposed by Felisati et al. ${ }^{10}$. The former tend to uniformly require a combined approach for OAC closure and sinus drainage, that yields its best results when performed during the same surgical session ${ }^{25,26}$. The same principle applies whenever an iatrogenic $\mathrm{OAC}$ formation is expected during 


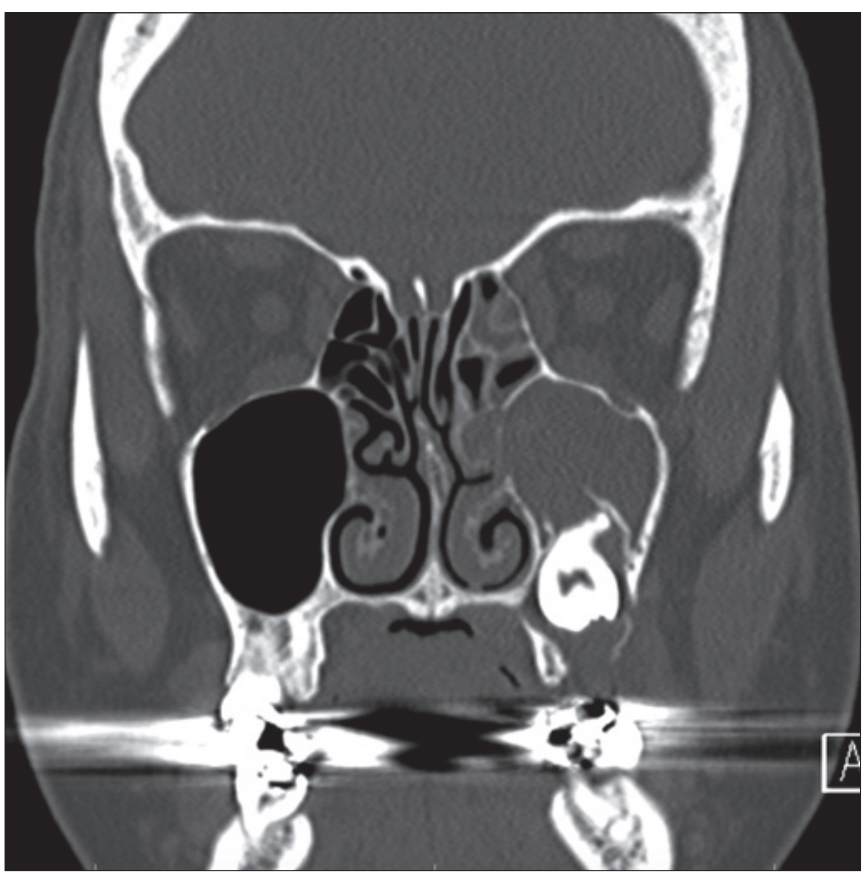

Figure 2. Coronal CT image showing unerupted teeth which determined a sinusitis process involving the ipsilateral maxillary sinus, ostiomeatal complex and, partially, anterior ethmoid sinus. Furthermore, the infection progressively led to the formation of oro-antral communication. A combined approach was performed in order to drain and ventilate the involved sinuses via an endoscopic approach and to remove the unerupted teeth and close the oro-antral communication from an intraoral approach.

ODS treatment (e.g. when the dental surgeon planned the extraction of a tooth with roots extending into the maxillary sinus or when a large odontogenic cyst requires an intraoral approach for its removal). Also, in these cases, a combined intraoral-endonasal approach should be preferred.

Patient without OAC or where an iatrogenic OAC is not expected can be managed with ESS alone. In these cases, the dental treatment can be performed during a different surgical session, which should precede ESS in low to mild symptomatic patients and follow ESS in heavily symptomatic patients ${ }^{9}$.

\section{ODS following maxillary sinus grafting}

Maxillary sinus grafting (MSG) is a common pre-implantologic procedure which gained increasing popularity from the mid-eighties in patients lacking enough vertical bone height to warrant safe dental implant positioning. The procedure aims at promoting osteoinduction and osteoconduction by positioning grafts (ranging from autologous bone to hydroxyapatite) underlying the maxillary sinus Schneiderian membrane from an intraoral approach. Implant placement might be immediate or delayed, i.e. following the consolidation of the newly formed bone, according to the initial bone

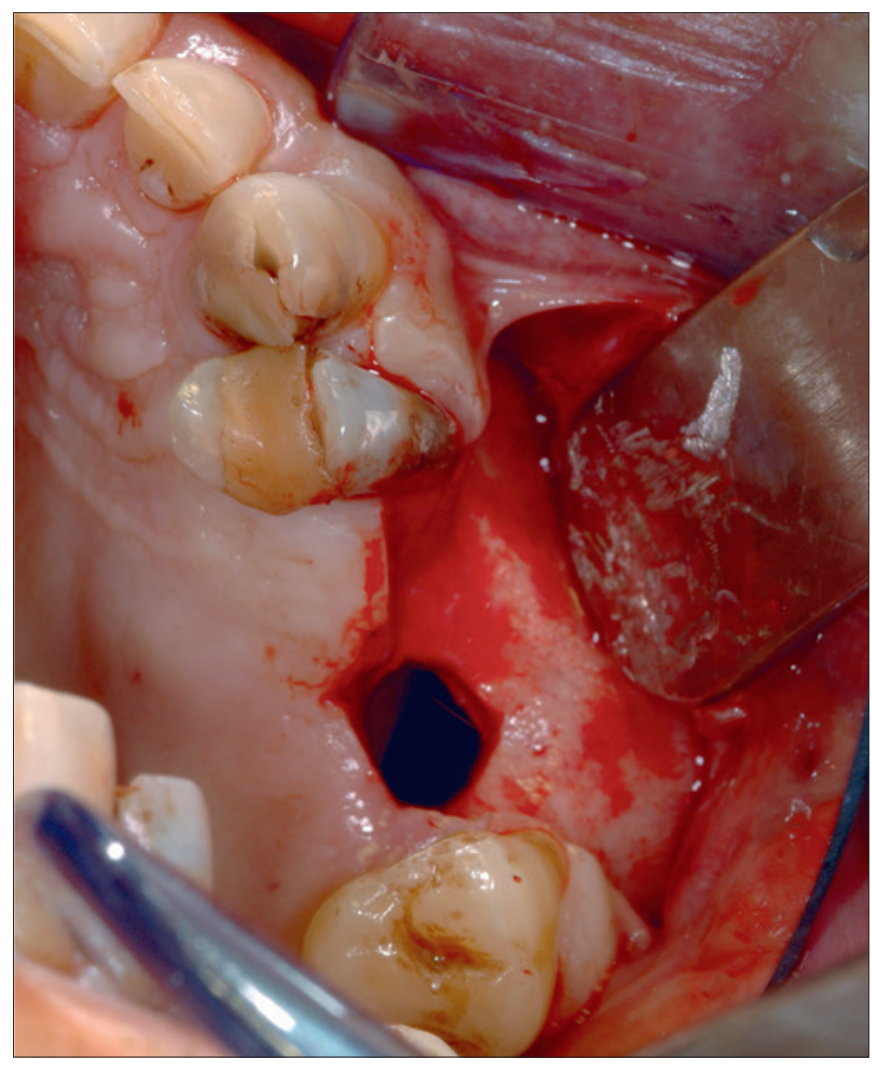

Figure 3. Intraoperative photograph of oroantral communication. A vestibular Rehrmann flap has been raised in order to provide a tension-free closure of the communication.

vertical height before grafting. Immediate implant placement can be proposed only if the initial vertical bone height is enough to warrant implant stability, with the graft providing only a further reinforcement). Sinus complications may follow MSG mainly because of Schneiderian membrane perforation during the grafting, with consequent migration of the graft inside the sinus, or due to the unnoticed presence of otolaryngological contraindications to grafting. Given the significant disruption of the maxillary sinus homeostasis ensuing the sinus floor elevation, some authors postulated that a healthy sinus, with a patent ostium and efficient mucociliary clearance, was a basic requirement for avoiding sinusitis processes ${ }^{27,28}$. While the collaboration between otolaryngologist and dental surgeons in evaluating candidates to MSG in order to minimize complications is almost mandatory, this topic goes beyond the scope of this chapter (see also ${ }^{29}$ ). Nevertheless, treating ODS ensuing MSG is another matter of strict cooperation between these specialists. To navigate this scenario and evaluate the requirement of combined approaches, several points must be taken into account: 1) dislocation of grafting material into the sinus; 2) development of a sinusitis process; and 3) the presence of an OAC. 


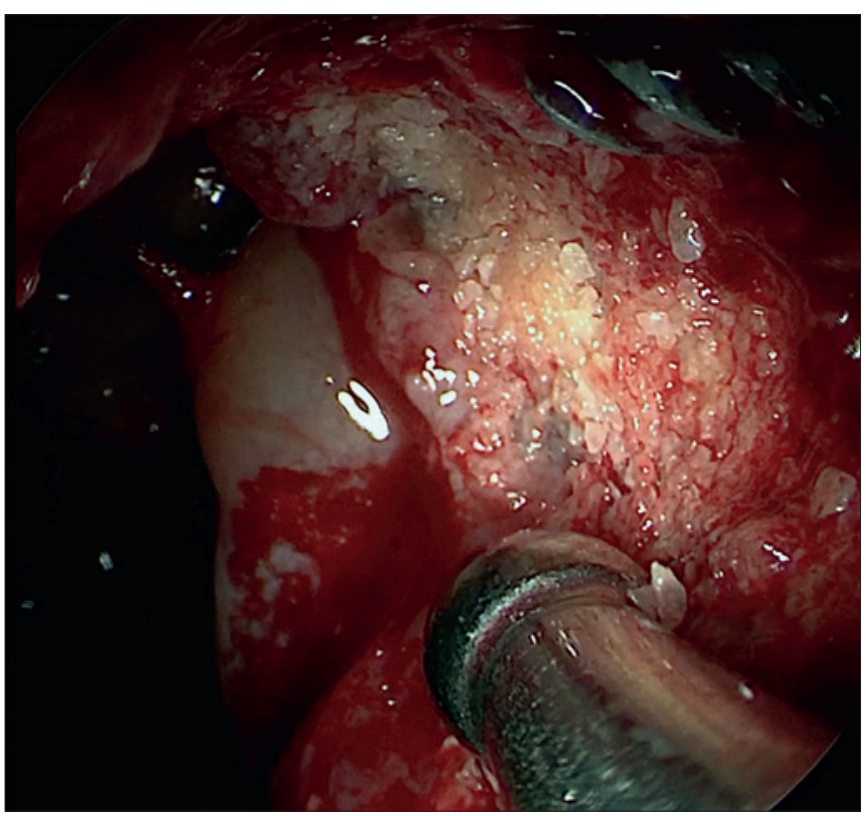

Figure 4. Endoscopic view of the right maxillary sinus obtained via a trans alveolar approach. A combined approach, both in operative and visualization terms, is required in post maxillary sinus grafting patients in order to completely remove the displaced and infected grafting material, in this specific case along with a non-osseointegrated implant.

First and foremost, if an acute infection follows MSG, appropriate imaging should be used to identify whether the grafting dislocated into the sinus. If the graft is still confined under the Schneiderian membrane, it will be up to the dental specialist to follow specific post grafting guidelines counselling whether trying to salvage the graft with appropriate antibiotic therapy or removing it via the same oral approach used when performing the MSG ${ }^{27}$. If the graft is displaced into the sinus, neither the oral approach nor nasal endoscopy is single-handedly enough to remove all the particles. In these patients, a combined approach is mandatory, with a wide antrostomy and oral access allowing the use of angled scopes and curved instruments to ventilate the sinus and remove the particles (Fig. 4). In our experience, a thorough particle removal, pivotal in maximizing therapeutic success rates in these patients, can be achieved only employing scopes and instruments both through the nose and the oral access, in order to allow the best maxillary sinus visualization ${ }^{30}$.

Secondly, the specialist should investigate whether a sinus inflammatory process has taken place, with careful clinical evaluation of the patient coupled with endoscopy and/or appropriate imaging. Even in the few cases where sinusitis ensues MSG but without graft infection and displacement (e.g. if the sinusitis ensues months after the grafting, leaving enough time for osseointegration), an endoscopic endo- nasal approach is required to open the ostiomeatal complex and ventilate the sinus. As a general rule, if the graft is not displaced into the sinus, oral access for graft removal is not required.

Last, the presence of residual OAC communication must be properly evaluated also in post-MSG patients. A residual OAC, which often appears in correspondence to the bony window used for grafting, makes an intraoral approached closure mandatory.

\section{ODS following dental implants placement}

ODS may follow implants placement going awry for three main reasons: 1) implants may lose (or never achieve at all) osseointegration and dislocate into the mouth/sinuses leaving an OAC behind; 2) implants may dislocate into the sinuses, sometimes leading also to sinusitis, or 3 ) implants may develop peri-implant osteitis (or peri-implantitis) and act as a Trojan horse in allowing bacteria to reach the otherwise sterile sinusal spaces ${ }^{31}$.

The first scenario requires a combined approach were sinus drainage is achieved endoscopically and OAC closure is performed transorally. Implants displaced into the sinuses may be retrieved either transorally or via nasal endoscopy according to position and surgeons' preference.

The second scenario, sinusal implant displacement, must be treated endoscopically in case of sinusitis, draining sinuses and removing the implant. In case of implant displacement without sinusitis, the retrieval can be performed either transorally, via a bony window or canine fossa access, or endoscopically ${ }^{32,33}$.

Cases in which dental implants are, at least apparently, osseointegrated require the most careful planning and diagnostic workup (Fig. 5). While multidisciplinary statements suggest primary endoscopic surgery aimed at treating the patient without removing the implant ${ }^{9}$, the surgeon must take into account that failure to recognize an unstable and infected implant is a frequent cause of treatment failure ${ }^{10,34,35}$. Indeed, unnecessary implant removal might enhance the risk of OAC and inevitably burdens patients with further oral rehabilitation costs. Intraoral radiographs, orthopantomography and careful dental clinical evaluation can help in minimizing risks at both ends of the spectrum, though only sharing the diagnostic and therapeutic plan with the patient allows tailoring the treatment. In these patients, multidisciplinary collaboration represents more of a diagnostic need than a therapeutic tool. For the sake of completion, it has to be noted that implant penetration in the maxillary sinus is not per se an indication to implant removal and does not necessarily imply the development of a sinusitic process over time ${ }^{36}$. 


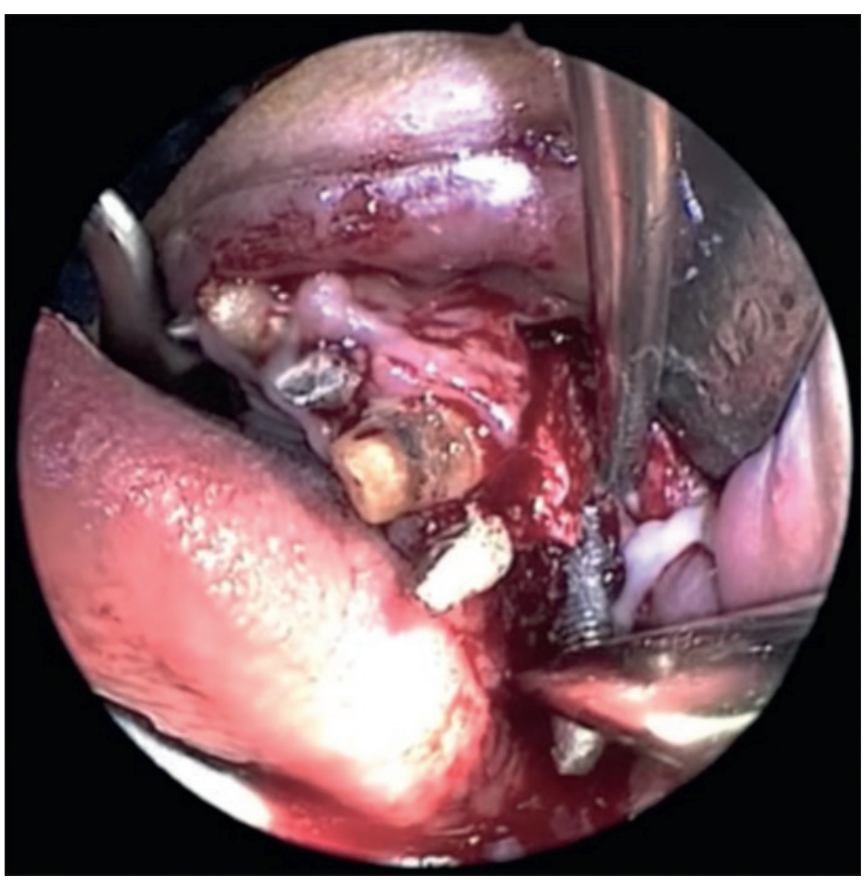

Figure 5. Intraoperative photograph showing the removal of an unstable dental fixture which developed a severe peri-implant infection, leading to sinusitis, in a patient with multiple infected implants.

\section{ODS during medication-related osteonecrosis of the jaw} (MRONJ)

OS following MRONJ is maybe the least studied scenario hereby presented, and the only scenario which is actually falling outside of Felisati classification ${ }^{10}$. Only three international groups presented MRONJ-related ODS cases in their series ${ }^{12,37,38}$. For these patients, intraoral access is recommended for removing necrotic bone ${ }^{12}$ and should be coupled with an adequately calibrated antrostomy in order to explore, drain and ventilate the sinus removing any further foreign body ${ }^{37,38}$. While the cooperation with an oral surgeon seems based on solid scientific premises, MRONJrelated ODS requires at present further exploration to enhance patients' treatment.

\section{Conclusions}

ODS represent, by definition, a border condition between otolaryngology and dental science and, from a holistic perspective, cannot be managed without a proficuous collaboration between specialists.

Albeit more prospective and rigorous studies are badly needed for determining the best treatment for each patient, the sheer variety of scenarios that may be encountered should be enough to encourage mutual collaboration between ENTs and dentists, both for perfecting diagnostic and treatments and providing a solid scientific and medicolegal foundation for each intervention proposed to patients.

\section{References}

Bauer WH. Maxillary sinusitis of dental origin. Am J Orthod Oral Surg 1943;29:B133-B151. https://doi.org/10.1016/ s0096-6347(43)90011-0

2 Ferguson M. Rhinosinusitis in oral medicine and dentistry. Aust Dent J 2014;59:289-295. https://doi.org/10.1111/adj.12193

3 Fokkens WJ, Lund VJ, Hopkins C, et al. European Position Paper on rhinosinusitis and nasal polyps 2020. Rhinology 2020;58:1-464. https://doi.org/10.4193/Rhin20.600

4 Orlandi RR, Kingdom TT, Hwang PH. International Consensus Statement on Allergy and Rhinology: rhinosinusitis executive summary. Int Forum Allergy Rhinol 2016;6:S3-S21. https://doi.org/10.1002/ alr.21694

5 Hoskison E, Daniel M, Rowson JE, et al. Evidence of an increase in the incidence of odontogenic sinusitis over the last decade in the UK. J Laryngol Otol 2012;126:43-46. https://doi.org/10.1017/ S0022215111002568

6 Allevi F, Fadda GL, Rosso C, et al. Diagnostic criteria for odontogenic sinusitis: a systematic review. Am J Rhinol Allergy 2020 Nov 25. https://doi.org/10.1177/1945892420976766. Online ahead of print.

7 Workman AD, Granquist EJ, Adappa ND. Odontogenic sinusitis: developments in diagnosis, microbiology, and treatment. Curr Opin Otolaryngol Head Neck Surg 2018;26:27-33. https://doi.org/10.1097/ MOO.0000000000000430

8 Saibene AM, Vassena C, Pipolo C, et al. Odontogenic and rhinogenic chronic sinusitis: a modern microbiological comparison. Int Forum Allergy Rhinol 2016;6:41-45. https://doi.org/10.1002/alr.21629

9 Craig JR, Tataryn RW, Aghaloo TL, et al. Management of odontogenic sinusitis: multidisciplinary consensus statement. Int Forum Allergy Rhinol 2020;10:901-912. https://doi.org/10.1002/alr.22598

10 Felisati G, Chiapasco M, Lozza P, et al. Sinonasal complications resulting from dental treatment: outcome-oriented proposal of classification and surgical protocol. Am J Rhinol Allergy 2013;27:e101-106. https://doi.org/10.2500/ajra.2013.27.3936

11 Saibene AM, Collurà F, Pipolo C, et al. Odontogenic rhinosinusitis and sinonasal complications of dental disease or treatment: prospective validation of a classification and treatment protocol. Eur Arch Otorhinolaryngol 2019;276:401-406. https://doi.org/10.1007/ s00405-018-5220-0

12 Fadda GL, Berrone M, Crosetti E, et al. Monolateral sinonasal complications of dental disease or treatment: when does endoscopic endonasal surgery require an intraoral approach? Acta Otorhinolaryngol Ital 2016;36:300-309. https://doi.org/10.14639/0392-100X-904

13 Ye J, Hu S, Bian M, Yuan J, et al. Endoscopic sinus surgery plays an essential role in systematic treatment of odontogenic maxillary sinusitis. Laparosc Endosc Robot Surg 2018;1;19-23. https://doi. org/10.1016/j.lers.2018.03.001

14 Rosenfeld RM, Piccirillo JF, Chandrasekhar SS, et al. Clinical practice guideline (update): adult sinusitis. Otolaryngol Head Neck Surg 2015;152:S1-S39. https://doi.org/10.1177/0194599815572097

15 Wuokko-Landén A, Blomgren K, Välimaa H. Acute rhinosinusitis are we forgetting the possibility of a dental origin? A retrospective study of 385 patients. Acta Otolaryngol 2019;139:783-787. https:// doi.org/10.1080/00016489.2019.1634837

16 Fredriksson MV, Öhman A, Flygare L, et al. When maxillary sinusitis does not heal: findings on CBCT scans of the sinuses with a particular focus on the occurrence of odontogenic causes of maxillary sinusi- 
tis. Laryngoscope Investig Otolaryngol 2017;2:442-446. https://doi. org/10.1002/lio2.130

17 Bajoria AA, Sarkar S, Sinha P. Evaluation of odontogenic maxillary sinusitis with cone beam computed tomography: a retrospective study with review of literature. J Int Soc Prev Community Dent 2019;9:194204. https://doi.org/10.4103/jispcd.JISPCD_435_18

18 Krivopalov AA, Glazev IE, Piskunov IS, et al. Cone beam computer tomography as a diagnostic method for odontogenic maxillary sinusitis. Mod Prob Sci Educ 2020;2:4. https://doi.org/10.17513/ spno.29576

19 Ungar OJ, Yafit D, Kleinman S, et al. Odontogenic sinusitis involving the frontal sinus: is middle meatal antrostomy enough? Eur Arch Otorhinolaryngol 2018;275:2291-5. https://doi.org/10.1007/ s00405-018-5076-3

20 Safadi A, Kleinman S, Oz I, et al. Questioning the justification of frontal sinusotomy for odontogenic sinusitis. J Oral Maxillofac Surg 2020;78:762-770. https://doi.org/10.1016/j.joms.2019.12.025

${ }_{21}$ Craig JR, McHugh CI, Griggs ZH, et al. Optimal timing of endoscopic sinus surgery for odontogenic sinusitis. Laryngoscope 2019;129:1976-1983. https://doi.org/10.1002/lary.28001

22 Crovetto-Martinez R, Martin-Arregui FJ, Zabala-Lopez-de-Maturana A, et al. Frequency of the odontogenic maxillary sinusitis extended to the anterior ethmoid sinus and response to surgical treatment. Medicina Oral Patología Oral y Cirugia Bucal 2014:19:e409-e413. https:// doi.org/10.4317/medoral.19629

23 Molteni M, Bulfamante AM, Pipolo C, et al. Odontogenic sinusitis and sinonasal complications of dental treatments: a retrospective evaluation on 480 patients and a critical assessment of the current classification. Acta Otorhinolaryngol Ital 2020;40:282-289. https:// doi.org/10.14639/0392-100X-N0457

24 Guerra-Pereira I, Vaz P, Faria-Almeida R, et al. CT maxillary sinus evaluation - a retrospective cohort study. Med Oral Patol Oral Cir Bucal 2015;20:e419-e426. https://doi.org/10.4317/medoral.20513

25 Andric M, Saranovic V, Drazic R, et al. Functional endoscopic sinus surgery as an adjunctive treatment for closure of oroantral fistulae: a retrospective analysis. Oral Surg Oral Med Oral Pathol Oral Radiol Endod 2010;109:510-516. https://doi.org/10.1016/j.tripleo.2009.10.028

26 Fusetti S, Emanuelli E, Ghirotto C, et al. Chronic oroantral fistula: combined endoscopic and intraoral approach under local anesthesia. Am J Otolaryngol 2013;34:323-326. https://doi.org/10.1016/j. amjoto.2012.12.015

27 Testori T, Drago L, Wallace SS, et al. Prevention and treatment of postoperative infections after sinus elevation surgery: clinical consensus and recommendations. Int J Dent 2012;2012:365809. https://doi. org/10.1155/2012/365809
28 Pignataro L, Mantovani M, Torretta S, et al. ENT assessment in the integrated management of candidate for (maxillary) sinus lift. Acta Otorhinolaryngol Ital 2008;28:110-119.

29 Felisati G, Saibene AM, Chiapasco M, et al. ENT contraindications to maxillary sinus grafting prior to or in association with oral implant placement. In: Felisati G, Chiapasco M, editors. Sinonasal complications of dental disease and treatment. Stuttgart, Germany: Thieme Verlag; 2015. pp. 131-148.

30 Chiapasco M, Felisati G, Zaniboni M, et al. The treatment of sinusitis following maxillary sinus grafting with the association of functional endoscopic sinus surgery (FESS) and an intra-oral approach. Clin Oral Implants Res 2013;24:623-629. https://doi. org/10.1111/j.1600-0501.2012.02440.x

31 Chiapasco M, Felisati G, Maccari A, et al. The management of complications following displacement of oral implants in the paranasal sinuses: a multicenter clinical report and proposed treatment protocols. Int J Oral Maxillofac Surg 2009;38:1273-1278. https://doi. org/10.1016/j.ijom.2009.09.001

32 Mantovani M, Pipolo C, Messina F, et al. Antral retriever and displaced dental implants in the maxillary sinus. J Craniof Surg 2011;22:22752277. https://doi.org/10.1097/scs.0b013e3182327125

33 Biglioli F, Goisis M. Access to the maxillary sinus using a bone flap on a mucosal pedicle: preliminary report. J Craniomaxillofac Surg 2002;30:255-259. https://doi.org/10.1054/jcms.2002.0279

34 Kim SJ, Park JS, Kim HT, et al. Clinical features and treatment outcomes of dental implant-related paranasal sinusitis: a 2-year prospective observational study. Clin Oral Implants Res 2016;27:e100-104. https://doi.org/10.1111/clr.12570

35 Chen Y-W, Huang C-C, Chang P-H, et al. The characteristics and new treatment paradigm of dental implant-related chronic rhinosinusitis. Am J Rhinol Allergy 2013;27:237-244. https://doi.org/10.2500/ ajra.2013.27.3884

36 Abi Najm S, Malis D, El Hage M, et al. Potential adverse events of endosseous dental implants penetrating the maxillary sinus: long-term clinical evaluation. Laryngoscope 2013;123:2958-2961. https://doi. org/10.1002/lary.24189

37 Zirk M, Dreiseidler T, Pohl M, et al. Odontogenic sinusitis maxillaris: a retrospective study of 121 cases with surgical intervention. J Craniomaxillofac Surg 2017;45:520-525. https://doi.org/10.1016/j. jcms.2017.01.023

38 Costa F, Emanuelli E, Franz L, et al. Single-step surgical treatment of odontogenic maxillary sinusitis: a retrospective study of 98 cases. J Craniomaxillofac Surg 2019;47:1249-1254. https://doi.org/10.1016/j. jcms.2019.04.012 